\title{
Neurological and mental health outcomes among conventional and organic farmers in Indiana, USA
}

\author{
Khalid M Khan ${ }^{1, A-F}$, Retushi Baidya ${ }^{2, B-D, F}$, Ashamsa Aryal1,C-D,F, James R Farmer, ${ }^{3, E-F}$, Julia Valliant ${ }^{4, B-C, F}$ \\ ${ }^{1}$ Department of Environmental and Occupational Health, School of Public Health, Indiana University, Bloomington, Indiana, \\ USA \\ ${ }^{2}$ Department of Epidemiology and Biostatistics, School of Public Health, Indiana University, Bloomington, Indiana, USA \\ ${ }^{3}$ Department of Recreation, Park and Tourism Studies, School of Public Health, Indiana University, Bloomington, \\ Indiana, USA \\ ${ }^{4}$ Vincent and Elinor Ostrom Workshop in Political Theory and Policy Analysis, Indiana University, Bloomington, Indiana, USA \\ $A$ - research concept and design; $B$ - collection and/or assembly of data; $C$ - data analysis and interpretation; \\ $D$ - writing the article; $E$ - critical revision of the article; $F$ - final approval of article
}

\begin{abstract}
Khan KM, Baidya R, Aryal A, Farmer JM, Valliant J. Neurological and mental health outcomes among conventional and organic farmers in
\end{abstract} Indiana, USA. Ann Agric Environ Med. 2018; 25(2): 244-249. doi: 10.26444/aaem/75113

\section{Abstract}

Introduction. Every farming method, whether conventional or organic, has been associated with some sort of risky behaviors leading to health issues among farmers. Substantial evidence is not available in the literature to determine whether the magnitudes of health outcomes vary between conventional and organic farmers. The study investigated whether selfreported neurological and mental health symptoms differ between conventional and organic farmers living in Indiana, USA.

Materials and method. A self-reported questionnaire survey collected information from 200 conventional and 157 organic farmers of Indiana on demographic characteristics, depression and neurological symptoms. Statistical analyses were conducted to observe the differences in self-reported symptoms by groups of farmers.

Results. It was observed that the conventional farmers had significantly higher age-adjusted mean neurological symptom score $(p<0.01)$ than the organic farmers. Regression models revealed positive and significant associations of conventional farming with total $(\beta=1.34 ; p=0.02)$, sensory $(\beta=0.83 ; p=0.001)$ and behavioural $(\beta=0.09 ; p=0.03)$ symptoms after accounting for age, income, education and years in farming. Positive but non-significant associations were also observed in conventional farmers with cognitive and motor symptoms, and with all subscales of depression symptoms in the adjusted models.

Conclusion. The findings obtained suggest the importance of a larger study to further explain the difference in mental and neurological health effects in these two categories of farmers.

\section{Key words}

conventional farming, organic farming, health effects, depression, neurological symptoms

\section{INTRODUCTION}

Occupational health concerns associated with conventional methods of farming are increasing due to the use of toxic agrochemicals and risky farming practices in the United States [1]. Organic farming methods, as defined by the United States Department of Agriculture (USDA) National Organic Program (NOP), apply products using health-friendly methods that preserve the environment and minimize the use of synthetic materials including synthetic pesticides and antibiotics $[2,3]$. However, health concerns for organic farmers are also evident in the literature as they are exposed to toxic organic materials and pesticides derived from natural sources [4-8]. Although both conventional and organic farmers report respiratory health outcomes the types of outcomes may be different. For instance, a survey conducted in the Netherlands found higher risk of wheezing and shortness of breath in conventional farmers but higher risk

Address for correspondence: Khalid M Khan, Department of Environmental and Occupational Health, School of Public Health, Indiana University, 47405 Bloomington, United States

E-mail:kmkhan@indiana.edu

Received: 25.04.2017; accepted: 19.06.2017; first published: 09.01.2018 of hay fever in organic farmers [9]. Whether such differences in the reporting of other health outcomes exist between these two groups of farmers are not quite clear in the literature.

Many synthetic and natural pesticides, used more frequently by conventional and organic farmers, respectively, may be associated with occupational and environmental health concerns due to various levels of carcinogenic, mutagenic, teratogenic or clastogenic toxicities [4-8]. Associations of pesticide exposures with nervous system outcomes, such as abnormalities in nerve conduction, frequent neurological symptoms were demonstrated in epidemiological studies across the globe [10-16]. Pesticide exposures demonstrated dose-dependent associations with various mental health outcomes such as depressions and anxieties in several animal models [17-19]. A prospective epidemiological study of farmers in Iowa and North Carolina supported these toxicological data, because it found significant association between high cumulative pesticide exposure and depression amongst pesticide applicators, after accounting for potential sociodemographic and occupational confounding variables [20]. Similar effects of other pesticides were noted in studies of Costa Rican banana farmers [21] and Colorado residents living on conventional farms [22]. Various sociodemographic 
and occupational factors that may exist in the farm environment, including limitation in farm infrastructure, weak family structure, farm economy, bureaucracy, and other farming related uncertainty, may generate stressors for these farmers and may put them at risk of mental health issues, including depression and anxiety [23].

There is an upsurge in the reliance on conventional agricultural practices in the United States and elsewhere to increase the productivity of crops. Indiana, a hub for agronomy in the US, is dominated by farmers involved in conventional farming although the presence of growing numbers of certified organic farmers is also reported [24]. Since organic and conventional farmers use different types of chemical and biological agents, and may not have similar socioeconomic and lifestyle characteristics, the risk the health outcomes between these two farmers groups may vary. Several studies have compared these two groups of farmers with respect to respiratory symptoms, but they have been rarely compared for neurological and mental health symptoms. Therefore, a mail-in survey was carried out which included questions on various neurological and mental health symptoms on farmers involved in both conventional and organic farming practices in agricultural communities in Indiana, USA. The objective was to compare the frequencies and intensities of certain self-reported neurological and mental health symptoms between organic and conventional farmers.

\section{MATERIALS AND METHODS}

Participants and Study Site. Seven hundred potential participants involved in conventional farming were randomly selected from a list of USDA Farm Services Agency (FSA) database of Indiana farmers $(\mathrm{N}=13,706)$. At the same time, a list of organic certified farmers was downloaded from the National Organic Program's (NOP) certified farms listed on USDA's online database. Seven hundred male conventional farmers and 300 male organic farmers were randomly selected and listed. The two lists were then crosschecked to exclude any overlapping participant. A combined list of 1,000 potential participants from 92 counties across Indiana was generated, and subsequently invited them to participate in a survey by mail. Response were received from 387 participants. Thirty participants did not respond to most of the demographic questions. Participants who answered more than $75 \%$ of the demographic questions were included in the revised database for final analyses. The final sample for this study comprised 200 conventional and 157 organic farmers.

Survey Questionnaire. The survey was administered in midmarch 2015 and participants mailed the feedback between June -July of 2015. Ethical approval was obtained from the university Institutional Review Board prior to mailing the questionnaire. The questionnaire consisted of prompts related to farm environment, sociodemographic characteristics, symptoms of neurological and depression problems experienced by the participants within the past 30 days. Two different health-related instruments were incorporated to measure the symptoms. Questions on neurological symptoms were adopted from Agricultural Health Study (AHS) and National Institute of Health (NIH). This scale measured the neurological symptoms experienced by each participant on a scale of $0-3$, with 'not at all' coded as 0 and 'almost every day' coded as 3 . Fifteen symptoms were further classified into 4 subscales: behavioral, cognitive, sensory and motor symptoms. The total neurological score for each participant was calculated along with the score for all the subscales. Questions on depression symptoms were adopted from the Center for Epidemiologic Studies Depression Scale (CESD-R Scale). This scale measurese the 16 depressive symptoms experienced by each participant on a range similar to AHS scale. Each symptom had 4 response options on a scale of $0-3$, with 'not at all' coded as 0 and 'almost every day' coded as 3 . Reverse coding was performed for 4 of the positive symptoms (i.e. symptom indicated absence of depression) with 'not at all' coded as 3 and 'almost every day' coded as 0 . All the symptoms were grouped into depressive, well-being, somatic, and interpersonal symptom subscales.

Statistical Analysis. Data were analyzed using SPSS statistical software V. 22.0 and SAS 9.4. The differences between conventional and organic farmers in terms of sociodemographic and health characteristics were determined by chi-squared test for categorical variables and independent sample t-test for continuous variables. Average score for neurological and depression symptoms were calculated along with their subscale scores by adding-up the response code for each symptom under each scale or subscale. Regression analyses using linear models were conducted on SAS to measure the regression coefficient after accounting for the potential confounding variables. After reviewing the current literature, potential confounding variables were identified that could differ between the 2 groups. We evaluated whether the inclusion of potential confounding variables changed the estimated regression coefficients relating group (conventional vs. organic farmers) to the outcome by more than 0.5 standard errors. Variables that met this criteria, such as income, education, age and years spent in farming, were included in the final regression models.

\section{RESULTS}

Sociodemographic characteristics. Conventional farmers were significantly older than the organic farmers (mean age 60.1 years vs. 46.9 years) (Tab. 1). There was also a significant difference in the duration of farming, as conventional farmers were engaged in farming for a longer period of time (mean 36.9 years), compared to the organic (mean 18.1 years). Even though the percentage of conventional farmers having health insurance was significantly higher, no significant difference was observed on self-reported health status between the 2 types of farm participants (Tab. 1).

Neurological symptoms. Conventional farmers demonstrated a significantly higher frequency of neurological symptoms, as shown by a significantly higher mean of total symptom score compared to the organic farmers, even after accounting for age ( $\mathrm{p}=0.05)$ (Tab. 2). When the differences between these two groups were examined under each of the symptom subscales, conventional farmers also demonstrated higher symptom scores across all 4 subscales of neurological symptoms, although only the sensory subscale score was found to be significantly higher after accounting for age $(p=0.001)$. The regression models in Table 3 demonstrated 
Table 1. Sociodemographic characteristics of the participants

\begin{tabular}{|c|c|c|c|c|}
\hline Variables & $\begin{array}{c}\text { Conventional } \\
\text { Farmers } \\
\text { Mean (SD)/ \% (n) }\end{array}$ & $\begin{array}{c}\text { Organic } \\
\text { Farmers } \\
\text { Mean }(\mathrm{SD}) / \%(\mathrm{n})\end{array}$ & Min, Max & $\begin{array}{c}\text { p-values } \\
\text { (between } \\
\text { groups) }\end{array}$ \\
\hline Age & $60.1(13.9)$ & 46.9 (12.7) & $25.0,91.0$ & $<0.001$ \\
\hline $\begin{array}{l}\text { Length of farming } \\
\text { in years }\end{array}$ & 36.9 (15.5) & $18.1(12.4)$ & $1.0,80.0$ & $<0.001$ \\
\hline $\begin{array}{l}\text { Income } \\
<\$ 75,000 \\
>\$ 75,000\end{array}$ & $\begin{array}{c}48.5 \%(97) \\
51.5 \%(103)\end{array}$ & $\begin{array}{l}59.9 \%(94) \\
40.1 \%(63)\end{array}$ & NA & 0.01 \\
\hline $\begin{array}{l}\text { Education } \\
\text { Less than High } \\
\text { school } \\
\text { High school or } \\
\text { above }\end{array}$ & $\begin{array}{l}43 \%(86) \\
57 \%(114)\end{array}$ & $\begin{array}{c}75.8 \%(119) \\
24.2 \%(38)\end{array}$ & NA & $<0.001$ \\
\hline $\begin{array}{l}\text { Marital status } \\
\text { Married Widowed/ } \\
\text { Divorced/Single }\end{array}$ & $\begin{array}{c}85.5 \%(171) \\
14.5 \%(29)\end{array}$ & $\begin{array}{c}94.3 \%(148) \\
5.7 \%(9)\end{array}$ & NA & 0.03 \\
\hline $\begin{array}{l}\text { Applied pesticides } \\
\text { in farm } \\
\text { Yes } \\
\text { No }\end{array}$ & $\begin{array}{l}71.0 \%(142) \\
29.0 \%(58)\end{array}$ & $\begin{array}{c}5.7 \% \text { (9) } 94.3 \% \\
\text { (148) }\end{array}$ & NA & $<0.001$ \\
\hline $\begin{array}{l}\text { Insurance } \\
\text { Yes } \\
\text { No }\end{array}$ & $\begin{array}{c}96.4 \%(187) \\
3.6 \%(7)\end{array}$ & $\begin{array}{c}30.7 \%(47) \\
94.3 \%(148)\end{array}$ & NA & $<0.001$ \\
\hline $\begin{array}{l}\text { General health } \\
\text { condition } \\
\text { Excellent } \\
\text { Very good } \\
\text { Good } \\
\text { Fair }\end{array}$ & $\begin{array}{c}20.5 \%(41) \\
47 \%(94) \\
25.5 \%(51) \\
7 \%(14)\end{array}$ & $\begin{array}{c}22.3 \%(35) \\
45.9 \%(72) \\
24.2 \%(38) \\
7.6 \%(12)\end{array}$ & NA & 0.48 \\
\hline
\end{tabular}

positive association between conventional farming and total symptom score $(\beta=1.34 ; \mathrm{p}=0.02)$ after accounting for potential covariates, including age, income, education and years involved in farming. When the exposure-outcome relationship for each of the four subscales was analyzed. It was observed that there was a consistency of this positive association across all 4 subscales of neurological symptoms. Associations for behavioral $(b=0.09 ; \mathrm{p}=0.03)$ and sensory symptom scores $(b=0.83 ; p=0.001)$ were statistically significant in the adjusted models, whereas associations for cognitive and motor symptoms were positive but non-significant.

Depression symptoms. Based on the total and subscale CESD scores, conventional farmers demonstrated marginally
Table 3. Associations of farming practices (Conventional vs. Organic) with neurological and depression symptom scores.

\begin{tabular}{lcccc}
\hline Outcome variables & $\begin{array}{c}\text { Unadjusted } \\
\text { models }\end{array}$ & & $\begin{array}{c}\text { Adjusted } \\
\text { models* }\end{array}$ \\
\hline Behavioural symptom score & $0.05(0.15)$ & 0.26 & $0.09(0.19)$ & $\mathbf{0 . 0 3}$ \\
\hline Cognitive symptom score & $0.01(0.12)$ & 0.47 & $0.07(0.16)$ & 0.32 \\
\hline Sensory symptom score & $0.79(0.21)$ & $<0.001$ & $0.83(0.26)$ & $\mathbf{0 . 0 0 1}$ \\
\hline Motor symptom score & $0.31(0.16)$ & 0.02 & $0.35(0.18)$ & 0.32 \\
\hline Total neurological symptom score & $1.21(0.52)$ & 0.01 & $1.34(0.65)$ & $\mathbf{0 . 0 2}$ \\
\hline CESD depressive act & $0.12(0.21)$ & 0.29 & $0.28(0.29)$ & 0.15 \\
\hline CESD well-being & $0.14(0.33)$ & 0.34 & $0.01(0.41)$ & 0.49 \\
\hline CESD somatic & $0.11(0.25)$ & 0.33 & $0.37(0.32)$ & 0.12 \\
\hline Total CESD depression score & $0.18(0.69)$ & 0.39 & $0.92(0.85)$ & 0.14 \\
\hline * Regression models adjusted for age, income, farming in years and education &
\end{tabular}

higher overall depression problems than the organic farmers. The differences between the 2 groups decreased further when the age-adjusted mean depression scores across all subscales were compared (Tab. 2). Conventional farming was positively associated with higher depression symptoms across all 4 subscales after accounting for income, age, education and years involved in farming, even though none of the regression coefficients were statistically significant (Tab. 3).

\section{DISCUSSION}

In this study, conventional farmers reported significantly higher neurological symptoms than the organic farmers after accounting for sociodemographic variables. At the same time, conventional farmers reported more symptoms of depression, although the frequencies were not significantly higher. Therefore, the results obtained for both neurological and mental health outcomes were consistent, indicating that more environmental and occupational risk factors may exist to a greater extent in conventional farm populations and contributing to the development of these outcomes. To the best of the authors' knowledge, the presented study is the first to compare the two groups of farmers for neurological symptoms. A small number of studies have compared these two groups using other health outcomes, with the majority predicting more health risks in conventional

Table 2. Comparison of neurological symptom scores between conventional and organic farmers

\begin{tabular}{|c|c|c|c|c|c|c|}
\hline \multirow[b]{2}{*}{ Neurological Symptoms } & \multicolumn{2}{|c|}{ Unadjusted Mean Scores (95\% CI) } & \multicolumn{4}{|c|}{ Age-adjusted Mean Scores $(95 \% \mathrm{Cl})$} \\
\hline & Conventional $(n=200)$ & Organic $(n=157)$ & $\mathrm{p}$-values & Conventional $(n=200)$ & Organic $(n=157)$ & p-values \\
\hline Behavioural & $0.81(0.61,0.99)$ & $0.71(0.49,0.93)$ & 0.49 & $0.85(0.66,1.05)$ & $0.64(0.42,0.87)$ & 0.17 \\
\hline Cognitive & $0.68(0.52,0.84)$ & $0.67(0.49,0.86)$ & 0.95 & $0.66(0.49,0.83)$ & $0.68(0.51,0.90)$ & 0.75 \\
\hline Sensory & $1.34(1.07,1.60)$ & $0.54(0.23,0.85)$ & $<0.001$ & $1.32(1.04,1.60)$ & $0.56(0.29,0.89)$ & 0.001 \\
\hline Motor & $0.65(0.44,0.85)$ & $0.34(0.10,0.57)$ & 0.03 & $0.59(0.38,0.80)$ & $0.41(0.16,0.66)$ & 0.30 \\
\hline \multicolumn{7}{|l|}{ Depression symptoms } \\
\hline Depressive act & $1.17(2.08)$ & $1.04(1.73)$ & 0.53 & $1.14(0.85,1.42)$ & $1.04(0.70,1.39)$ & 0.70 \\
\hline Well-being & $2.58(3.28)$ & $2.57(2.72)$ & 0.96 & $2.42(1.98,2.88)$ & $2.47(2.24,3.03)$ & 0.98 \\
\hline Somatic & $2.14(2.38)$ & $2.07(2.17)$ & 0.77 & $2.13(1.79,2.47)$ & $2.06(1.65,2.46)$ & 0.79 \\
\hline Interpersonal act & $0.31(0.72)$ & $0.19(0.54)$ & 0.08 & $0.26(0.15,0.34)$ & $0.23(0.13,0.35)$ & 0.90 \\
\hline
\end{tabular}


farmers. A recent study on Portuguese farmers identified elevated levels of micronuclei in the lymphocytes, increase in chromosomal aberrations and reduced level of B lymphocytes in conventional farmers, as opposed to organic farmers [25]. Another study in the Netherlands found lower risk of asthma-like symptoms in organic farmers than conventional farmers [9]. In contrast to these studies, a study of migrant European workers did not find any conclusive evidence about the difference in health status between these two groups [26]. The findings of the presented study are therefore consistent with the data provided by some European public health studies and promoters of organic farming which argue that the rejection or reduction of the use of chemical pesticides, artificial fertilizers and genetically-modified organisms may reduce the health concerns among farmers involved in organic farming $[9,27]$.

The survey questionnaire in the current study for the neurological symptoms was based on Swedish Q16 which, in different cultural settings, demonstrated the effects of pesticides on the nervous system among South African women farmers [28], Egyptian agricultural workers [13] exposed to organophosphorus pesticides, in addition to German [29] and Algerian [30] workers exposed to solvents. A modified version of Q16 was validated and used in a large US study on licensed pesticide applicators [15]. Although a higher number of symptoms were included in previous surveys, in the presented study, some symptoms which were found to be non-specific or autonomic (e.g. dizziness, headache, nausea, loss of appetite) were excluded, and therefore could not fall under any specific subscale $[13,15,16,31]$. Data from this study also provided identical findings to those presented by a large US Agricultural Health Study (AHS) on pesticideexposed male farmers [15]. It is anticipated that the sample of conventional farmers in this study might have been exposed to pesticides, resulting in more significant associations for cognitive and sensory symptoms, which were the two most dominant neurologic domains reported in the multistate AHS study [15].

For depression symptoms, the survey used The CESD-R Scale, which categorizes participants as "depressed" when the score becomes 16 or more. In the current study, the average score of participants was notably smaller due to inconsistencies in response for the scales. For example, some of the participants answered questions on depression but did not respond to the questions related to neurological outcomes. Even though the response rate for the scale was $83 \%$, the 'low' value of Cronbach's alpha revealed that the measure was fairly unidimensional. Several studies indicated that the combination of occupational and environmental stressors may contribute to increased risks of mental health outcomes and psychiatric disorders, such as suicide, even though information about these risk factors remains very limited [23, 34-36]. One study on 605 farm workers in the UK found that migrant organic farmworkers were happier and significantly less depressed than the conventional workers as they scored higher on Short Depression Happiness Scale (SDHS). This indicated a higher degree of mental peace associated with organic farming [26]. In the current study, a consistent but non-significantly lower depression among the organic farmers was found, perhaps due to the smaller sample size

This study has several limitations that should be taken into consideration while interpreting the results. It is acknowledged that self-reported outcome measures were used to examine the difference between the two groups of study participants. There was a risk of inaccurate reporting of these symptoms, especially when mailed survey questionnaire was used for data collection. The biological significance of these self-reported symptoms is unknown. However, it should be noted that the objective of the study was not to assess the prevalence of neurological diseases among two groups of Indiana farmers; the aim was rather to observe whether the intensity and frequency of symptoms were different in these two categories of farmers, which would allow the gathering of preliminary data for future epidemiological study. For instance, several studies on farmers exposed to agrochemicals demonstrated reduced cholinesterase activity and nerve conduction velocity $[37,38]$, suggesting that future survey studies should be complemented by biochemical assessment, including biomarkers of exposures and health effects and clinical examinations of nervous system and mental health outcomes. Another limitation was the lack of data related to participants' gender. While no sampling was performed for one gender over the other, it was not expected that the participant pool would be dissimilar to other agricultural studies where males generally dominated the respondent demographics, such as found in a recent survey of farmers in western Illinois where $78 \%$ of respondents were male [39].

Several participants in the presented study who were primarily involved in organic farming, also mentioned that they had minimal use of conventional farming methods in recent years, although additional information regarding this subgroup of organic farmers with a previous episode of acute agrochemical poisoning was not collected. Although the authors acknowledge that this is a limitation of the study, the number of organic farmer participants with a history of acute exposure was very small ( $6 \%$ of the organic farmers), and exclusion of these farmers from the dataset or addition of a categorical variable (i.e. recent acute exposure to agrochemical) in the regression models did not appreciably change the parameters of estimates (data not shown).

In this study sample, conventional farmers were significantly older than the organic farmers, which may have confounded the association between exposure (farming type) and health outcomes. After including this confounding variable the adjusted regression models still showed positive relationships of conventional farming with both neurological and mental health outcomes.

While health risks associated with conventional farming techniques, such as pesticide use, may seem plausible enough for the transition to organic practices, much research on the choice to farm organically indicate the complicated nature of the decision. Recent scholarship highlights that many motivations and factors affect the decision to farm organically and these factors are consistent across both country and cultural lines [40,41]. Prominently, environmental concerns with pollution and deleterious impacts [42], economic factors [43], and demographic differences between organic producers and conventional farmers (age, gender, and size of operation) $[44,45]$ are often highlighted throughout the literature as variables that predict the decision to pursue organic production methods. Additionally, health concerns and environmental health 'tragedies', including pesticide poisoning, are also posited as significant influential factors that affect farmers' decisions to the transition to organic production strategies [46]. In the presented study, limited 
exposure data on environmental and occupational factors did not allow the prediction of specific risk factors for neurological and mental health outcomes. It is observed that $71 \%$ of conventional farmers in this study reported pesticide applications during their farm operations, either by themselves or by their employers or co-workers, as opposed to only about $6 \%$ of the organic farmers. Therefore, the difference in health effects between the two groups may be attributable to differences in pesticide exposure in agricultural settings. Future studies might very well shed greater light on the relationships between various socioeconomic, behavioral, environmental and occupational risk factors with the nervous system and mental health outcomes in order to find the public health benefits of transitioning from conventional to organic production.

\section{CONCLUSION}

The results obtained in this study indicate that conventional farmers in Indiana are more likely to demonstrate neurological and mental health issues than organic farmers. Given the deleterious risks associated with conventional agricultural methods, this study further evidences the notion that policy considerations for pesticide usage is warranted across both professional fields and governance levels [47, 48]. Agencies serving rural, agricultural communities and citizens should consider policies that support greater awareness to those exposed to farm pesticides, particularly those located in specific geographic regions where specialized crops necessitate greater levels of pesticide application. Additionally, this study adds to the growing body of literature that should be considered for broader, landscape-level policy development informing governance by state and federal agencies. Coupled with literature that spans the human to the ecological dimension, evidence continues to accrue that calls into question the long-term implications of pesticide usage, questions that originated over sixty years ago [49].

\section{REFERENCES}

1. NRC: Pesticides in the Diets of Infants and Children. Committee on Pesticides in the Diets of Infants and Children. Commission on Life Sciences. Division on Earth and Life Studies. National Research Council: National Academic Press; 1993.

2. USDA: United States Department of Agriculture, Organic Agriculture. Available at http://www.usda.gov/wps/portal/usda/usdahome?conten tidonly $=$ true \&contentid=organic-agriculture.html. Accessed on June 10, 2016. 2016.

3. Hanson J, Dismukes R, Chambers W, Greene C, Kremen A. Risk and risk management in organic agriculture: Views of organic farmers. Renew Agr Food Syst. 2004; 19(4): 218-227.

4. Ames BN, Profet M, Gold LS. Dietary pesticides ( $99.99 \%$ all natural). Proceedings of the National Academy of Sciences of the United States of America 1990; 87(19): 7777-7781.

5. Ames BN, Profet M, Gold LS. Nature's chemicals and synthetic chemicals: comparative toxicology. Proceedings of the National Academy of Sciences of the United States of America 1990; 87(19): 7782-7786.

6. Hoar Zahm S, Weisenburger DD, Cantor KP, Holmes FF, Blair A. Role of the herbicide atrazine in the development of non-Hodgkin's lymphoma. Scand J Work Env Hea. 1993; 19(2): 108-114.

7. Karunanayake CP, Dosman JA, Pahwa P. Non-hodgkin's lymphoma and work in agriculture: Results of a two case-control studies in Saskatchewan, Canada. Indian J Occup Env Med. 2013; 17(3): 114-121.

8. Weisenburger DD. Human health effects of agrichemical use. Hum Pathol. 1993; 24(6): 571-576.
9. Smit LA, Zuurbier M, Doekes G, Wouters IM, Heederik D, Douwes J. Hay fever and asthma symptoms in conventional and organic farmers in The Netherlands. Occup Env Med. 2007; 64(2): 101-107.

10. Rosenstock L, Keifer M, Daniell WE, Mcconnell R, Claypoole K. Chronic Central-Nervous-System Effects of Acute Organophosphate Pesticide Intoxication. Lancet 1991; 338(8761): 223-227.

11. Hu RF, Huang XS, Huang JK, Li YF, Zhang C, Yin Y, Chen ZH, Jin YH, Cai JY, Cui F. Long- and Short-Term Health Effects of Pesticide Exposure: A Cohort Study from China. Plos One 2015; 10(6).

12. London L, Flisher AJ, Wesseling C, Mergler D, Kromhout H. Suicide and exposure to organophosphate insecticides: cause or effect? Am J Ind Med. 2005; 47(4): 308-321.

13. Khan K, Ismail AA, Abdel Rasoul G, Bonner MR, Lasarev MR, Hendy O, Al-Batanony M, Crane AL, Singleton ST, Olson JR, et al. Longitudinal assessment of chlorpyrifos exposure and self-reported neurological symptoms in adolescent pesticide applicators. BMJ open 2014; 4(3): e004177.

14. Cole DC, Carpio F, Julian J, Leon N. Assessment of peripheral nerve function in an Ecuadorian rural population exposed to pesticides. J Toxicol Env Hea Part A 1998; 55(2): 77-91.

15. Kamel F, Engel LS, Gladen BC, Hoppin JA, Alavanja MC, Sandler DP. Neurologic symptoms in licensed pesticide applicators in the Agricultural Health Study. Hum Exper Toxicol. 2007; 26(3): 243-250.

16. Kamel F, Hoppin JA. Association of pesticide exposure with neurologic dysfunction and disease. Environ Health Persp. 2004; 112(9): 950-958.

17. Costa LG, Giordano G, Guizzetti M, Vitalone A. Neurotoxicity of pesticides: a brief review. Front Biosci: a journal and virtual library 2008; 13: 1240-1249.

18. Werner FM, Covenas R. Classical neurotransmitters and neuropeptides involved in major depression: a review. Int J Neurosci. 2010; 120(7): 455-470.

19. Naismith SL, Norrie LM, Mowszowski L, Hickie IB. The neurobiology of depression in later-life: clinical, neuropsychological, neuroimaging and pathophysiological features. Prog Neurobiol. 2012; 98(1): 99-143.

20. Beseler CL, Stallones L, Hoppin JA, Alavanja MC, Blair A, Keefe T, Kamel F. Depression and pesticide exposures among private pesticide applicators enrolled in the Agricultural Health Study. Environ Health Persp. 2008; 116(12): 1713-1719.

21. Wesseling C, van Wendel de Joode B, Keifer M, London L, Mergler D, Stallones L. Symptoms of psychological distress and suicidal ideation among banana workers with a history of poisoning by organophosphate or n-methyl carbamate pesticides. Occup Environ Med. 2010; 67(11): 778-784.

22. Beseler CL, Stallones L. A cohort study of pesticide poisoning and depression in Colorado farm residents. Ann Epidemiol. 2008; 18(10): 768-774.

23. Torske MO, Hilt B, Glasscock D, Lundqvist P, Krokstad S. Anxiety and Depression Symptoms Among Farmers: The HUNT Study, Norway. J Agromed. 2016; 21(1): 24-33.

24. USDA: United States Department of Agriculture, Census of Agriculture. Available at http://www.agcensus.usda.gov/Publications/2007/. Accessed on January 14, 2016. 2007.

25. Costa C, Garcia-Leston J, Costa S, Coelho P, Silva S, Pingarilho M, Valdiglesias V, Mattei F, Dall'Armi V, Bonassi S, et al. Is organic farming safer to farmers' health? A comparison between organic and traditional farming. Toxicol Lett. 2014; 230(2): 166-176.

26. Cross P, Edwards RT, Hounsome B, Edwards-Jones G. Comparative assessment of migrant farm worker health in conventional and organic horticultural systems in the United Kingdom. Sci Total Environ. 2008; 391(1): 55-65.

27. Sorge US, Moon R, Wolff LJ, Michels L, Schroth S, Kelton DF, Heins B. Management practices on organic and conventional dairy herds in Minnesota. J Dairy Sci. 2016, 99(4): 3183-3192.

28. Motsoeneng PM, Dalvie MA. Relationship between Urinary Pesticide Residue Levels and Neurotoxic Symptoms among Women on Farms in the Western Cape, South Africa. Int J Environ Res Public Health 2015; 12(6): 6281-6299.

29. Ihrig A, Triebig G, Dietz MC. Evaluation of a modified German version of the Q16 questionnaire for neurotoxic symptoms in workers exposed to solvents. Occup Environ Med. 2001; 58(1): 19-23.

30. Sekkal S, Casas L, Haddam N, Bouhacina L, Scheers H, Taleb A, Nemery B. Sleep disturbances and neurotoxicity in workers exposed to hydrocarbons. An observational study from Algeria. Am J Ind Med. 2016; 59(2): 129-136.

31. Lundberg I, Hogberg M, Michelsen H, Nise G, Hogstedt C. Evaluation of the Q16 questionnaire on neurotoxic symptoms and a review of its use. Occup Environ Med. 1997; 54(5): 343-350. 
32. Radloff LS. The use of the Center for Epidemiologic Studies Depression Scale in adolescents and young adults. J Youth Adolescence 1991; 20(2): 149-166.

33. Radloff LS. The CES-D scale a self-report depression scale for research in the general population. Appl Psychol Meas. 1977; 1(3): 385-401.

34. Fraser CE, Smith KB, Judd F, Humphreys JS, Fragar LJ, Henderson A. Farming and mental health problems and mental illness. Int J Soc Psychiatr. 2005; 51(4): 340-349.

35. Stander VA, Hilton SM, Kennedy KR, Robbins DL. Surveillance of completed suicide in the Department of the Navy. Milit Med. 2004; 169(4): 301-306

36. Kallioniemi MK, Simola AJ, Kymalainen HR, Vesala HT, Louhelainen JK. Mental symptoms among Finnish farm entrepreneurs. Ann Agric Environ Med. 2009; 16(1): 159-168.

37. Dasgupta S, Meisner C, Wheeler D, Xuyen K, Thi Lam N. Pesticide poisoning of farm workers-implications of blood test results from Vietnam. Int J Hyg Environ Health. 2007; 210(2): 121-132.

38. Kimura K, Yokoyama K, Sato H, Nordin RB, Naing L, Kimura S, Okabe S, Maeno T, Kobayashi Y, Kitamura F, et al. Effects of pesticides on the peripheral and central nervous system in tobacco farmers in Malaysia: studies on peripheral nerve conduction, brain-evoked potentials and computerized posturography. Ind Health 2005; 43(2): 285-294.

39. Thompson AW, Reimer A, Prokopy LS. Farmers' views of the environment: the influence of competing attitude frames on landscape conservation efforts. Agr Hum Values 2015; 32(3): 385-399.

40. Darnhofer I, Schneeberger W, Freyer B. Converting or not converting to organic farming in Austria: Farmer types and their rationale. Agr Hum Values 2005; 22(1): 39-52.
41. Uematsu H, Mishra AK. Organic farmers or conventional farmers: Where's the money? Ecol Econ. 2012; 78: 55-62.

42. Sullivan S, McCann E, deYoung R, Erickson D. Farmers' attitudes about farming and the environment: A survey of conventional and organic farmers. J Agr Environ Ethic. 1996; 9(2): 123-143.

43. Veldstra MD, Alexander CE, Marshall MI. To certify or not to certify? Separating the organic production and certification decisions. Food Policy 2014; 49: 429-436.

44. Hall A, Mogyorody V. Organic farming, gender, and the labor process. Rural Sociol. 2007; 72(2): 289-316.

45. Burton M, Rigby D, Young T. Analysis of the determinants of adoption of organic horticultural techniques in the UK. J Agr Econ. 1999; 50(1): 48-63.

46. Brophy JT, Keith MM, Watterson A, Park R, Gilbertson M, MatickaTyndale E, Beck M, Abu-Zahra H, Schneider K, Reinhartz A, et al. Breast cancer risk in relation to occupations with exposure to carcinogens and endocrine disruptors: a Canadian case-control study. Environ Health-Glob. 2012: 11.

47. APHA: Toward a healthy, sustainable food system. Policy number 200712. Retrieved from http://www.apha.org/advocacy/policy/ policysearch/default.htm?id=1361. Accessed on November 10, 2016. 2007.

48. CDC: Center for Disease Control and Prevention. (2013). One health. Retrieved from http://www.cdc.gov/onehealth/. Accessed on November 15, 2016. 2013.

49. Carson R, Darling L, Darling L. Silent spring. Boston Cambridge, Mass.: Houghton Mifflin; Riverside Press; 1962. 